\title{
Brazilian Journal of Chemical

\section{DECHLORINATION OF ZINC OXIDE DUST DERIVED FROM ZINC LEACHING RESIDUE BY MICROWAVE ROASTING IN A ROTARY KILN}

\author{
Ma Ai-yuan ${ }^{1,2,3,4}$, Zheng Xue-mei ${ }^{1,2,3,4}$, Peng Jin-hui ${ }^{1,2,3,4}$, Zhang Li-bo ${ }^{1 * 2,3,4}$, \\ Chandrasekar Srinivasakannan ${ }^{5}$, Li Jing ${ }^{1,2,3,4}$ and Wei Cheng-long ${ }^{1,2,3,4}$ \\ ${ }^{1}$ Yunnan Provincial Key Laboratory of Intensification Metallurgy, Kunming 650093, China. \\ Phone: + 86 - 13888310177 \\ E-mail: libozhang77@163.com \\ ${ }^{2}$ National Local Joint Laboratory of Engineering Application of Microwave, \\ Energy and Equipment Technology, Kunming, Yunnan 650093, China. \\ ${ }^{3}$ Key Laboratory of Unconventional Metallurgy, Ministry of Education, Kunming 650093, China. \\ ${ }^{4}$ Faculty of Metallurgical and Energy Engineering, Kunming University of \\ Science and Technology, Kunming 650093, China. \\ ${ }^{5}$ Chemical Engineering Program, The Petroleum Institute, P.O. Box 2533, Abu Dhabi, United Arab Emirates.
}

(Submitted: May 28, 2014 ; Revised: March 30, 2015 ; Accepted: March 31, 2015)

\begin{abstract}
The dechlorination efficiency of zinc oxide dust using microwave roasting was investigated capitalizing on the different microwave absorbing capacities of the compounds such as chlorine, lead, and zinc oxide. The associated dechlorination reactions were discussed in detail and the effect of all the influencing parameters such as the air flow rate, steam flow rate, the roasting temperature, roasting duration, and the mixing rate were assessed to identify the optimal conditions. The results indicated that a near $93 \%$ dechlorination of zinc oxide dust could be achieved, which would satisfy the requirements of the wet smelting electrolysis process. The optimal process parameters were identified to be an air flow of $300 \mathrm{~L} / \mathrm{h}$, a steam flow of $8 \mathrm{~mL} / \mathrm{min}$, a stirring speed of $60 \mathrm{rpm}$, a roasting temperature of $650{ }^{\circ} \mathrm{C}$, and a roasting duration of $60 \mathrm{~min}$. Water vapor has an enhanced effect on dechlorination by microwave roasting.

Keywords: Zinc oxide dust; Microwave roasting; Selective heating; Dechlorination.
\end{abstract}

\section{INTRODUCTION}

The recovery of useful materials and metals from various secondary sources is of paramount importance due to economic and environmental benefits. Zinc is one of the most popular and versatile metals that finds wide applications, including plating, coating and alloying with other metals. Commercially zinc can be rated as the third most common nonferrous metal after aluminum and copper (Min et al., 2013; Vahidi et al., 2009; Li et al., 2012). Currently, the vast majority of metallic zinc is produced by the Roast-Leach-Electrowinning (RLE) process. In the leaching process, large amounts of leach residues are generated as insoluble substances that form a layer on the zinc surface during the acid leaching process, resulting in wastage of large amounts of valuable metals. Zinc oxide dust is presently obtained from zinc leach residue in a volatile revolving kiln, which contains significant amounts of $\mathrm{Zn}$. The zinc oxide dust consists of lead $(\mathrm{Pb})$, cadmium $(\mathrm{Cd})$, chromium $(\mathrm{Cr})$, nickel $(\mathrm{Ni})$, other non-ferrous metals, and a small amount of rare indium (In) metals (Zhao et al., 2013; Martins et al., 2014; Souza et al., 2007; Altundoğan et al., 1998; Jha et al., 2001; Xie 2008). Additionally, zinc dust has different levels of fluorine (F) and chlorine $(\mathrm{Cl})$, which strongly affect its utilization in zinc-based electrical products (Güresin and Topkaya

*To whom correspondence should be addressed 
1998). $\mathrm{F}$ and $\mathrm{Cl}$ ion concentrations in electrolytes must meet electrolysis requirements $(\mathrm{F}<80 \mathrm{mg} / \mathrm{L}$, $\mathrm{Cl}<100 \mathrm{mg} / \mathrm{L}$ ) in the zinc electrolysis process (Cinar Sahin et al., 2000; Lan et al., 2006). Currently, two major methods (Jiang et al., 2001; Qiu et al., 2008; Mason et al., 2006; Bodson 1997), roasting in multiple hearth furnaces or rotary kilns and caustic washing, are being adopted commercially for $\mathrm{F}$ and $\mathrm{Cl}$ pretreatment, which facilitate the removal of $\mathrm{F}$ and $\mathrm{Cl}$ from leach liquor. The removal efficiency of high fluoride and chloride concentrations using roasting approaches is low, and the method has problems of high temperature, high energy consumption, and so on. In the caustic washing, the alkali must be washed off the materials by water after caustic washing. The treatment of the waste caustic solution consumes a large amount of water and sulfuric acid, leading to difficulties in wastewater treatment and solid-liquid separation. This necessitates development of new methods for the removal of $\mathrm{F}$ and $\mathrm{Cl}$.

Microwave metallurgy is a highly efficient, clean, and green metallurgy technology that has developed rapidly (Onol and Saridede 2013). The unique heating characteristics of microwaves include low processing time, selective and volumetric heating, and a controllable heating process. Microwave metallurgy is successfully being adopted for microwave drying (Liang et al., 2011), microwave-assisted grinding (Salsman et al., 1996), microwave-assisted reduction (Jones et al., 2007; Chen et al., 2005), and microwave strengthening of leaching (Harahsheh and Kingman 2004). The material with a high-loss factor is heated preferentially by microwaves, and a phase interface is created with a large temperature gradient. Phase interface cracks are generated, which strengthen the phase separation. The loss factors of zinc chloride and lead chloride are 0.0836 and 0.0374 , which are higher than those of zinc oxide $(0.0357)$ and lead oxide (0.0098), respectively. Research shows that the microwave absorbance of chloride is strong, while that of $\mathrm{Zn}$ and $\mathrm{Pb}$ oxide is weak in zinc oxide dust (Peng and Yang 1997). Hence, utilizing the selective heating property of microwaves, the separation of impurities (chloride) as volatile components can be enhanced meeting the electrolysis process requirements.

The present study examines zinc leaching residue volatilization through roasting in a rotary kiln to remove $\mathrm{F}$ and $\mathrm{Cl}$ and to produce zinc oxide dust that is composed of complex materials with high levels of $\mathrm{Pb}$ and $\mathrm{Zn}$.

\section{MATERIALS AND METHODS}

\section{Experimental Materials}

The zinc oxide dust used in the experiments was received from $\mathrm{a} \mathrm{Pb}$ and $\mathrm{Zn}$ smelting enterprise in Yunnan Province in China. The particle size distribution of zinc oxide dust was analyzed with a Rise2002 laser particle size analyzer, and the results showed that the average particle size was $\mathrm{D}_{\mathrm{av}}=1.01$ $\mu \mathrm{m}$, with $99.87 \%$ of the dust below $3 \mu \mathrm{m}$ in particle size. After it was blended and then pre-dried to a constant weight in the drying oven of $80{ }^{\circ} \mathrm{C}$, the sample composition was characterized by X-ray diffraction and fluorescence (XRF) measurements. The main chemical composition of the zinc oxide dust is listed in Table 1, which reveals that zinc oxide dust has a high content of lead and zinc, as well as the content of chlorine.

\section{Analysis and Characterization}

A Scanning Electron Microscope (SEM) equipped with an Energy Dispersive Spectrometer (EDS) was used for analyzing the internal morphology and the elemental distribution of the zinc oxide dust.

The microstructure of the zinc oxide dust was shown in Figure 1, which shows that the agglomerate structure was observed in the zinc oxide dust. To obtain more information of the elemental distribution characteristics in the zinc oxide dust, especially that of $\mathrm{Cl}$, and the agglomerate zinc oxide dust was performed by X-ray EDS line scanning and X-ray EDS mapping, as shown in Figures 2 and 3. The EDS line scanning (see Figure 2) from the point (a) to the point (b) showed that the distribution of $\mathrm{Pb}$ and $\mathrm{Cl}$ are same, and it seems that $\mathrm{Pb}$ and $\mathrm{Cl}$ formed the chloride. The X-ray EDS mapping (see Figure 3) showed that $\mathrm{Pb}$ and $\mathrm{Cl}$ are enriched in the same location, and $\mathrm{Zn}$ is enriched in all regions of the agglomerate structure. $\mathrm{Cl}$ most likely formed the chlorides $\left(\mathrm{ZnCl}_{2}\right.$ and $\left.\mathrm{PbCl}_{2}\right)$ with $\mathrm{Zn}$ and $\mathrm{Pb}$.

Table 1: Chemical composition of zinc oxide dust determined by XRF analysis (mass fraction, \%).

\begin{tabular}{|l|c|c|c|c|c|c|}
\hline Composition & Zn & Pb & Cd & Fe & Mn & S \\
\hline Content (\%) & 78.57 & 13.99 & 1.21 & 2.28 & 0.20 & 1.93 \\
Composition & Cl & Si & Ca & In & F & \\
Content (\%) & 0.28 & 0.19 & 0.12 & 0.12 & $<0.01$ & \\
\hline
\end{tabular}




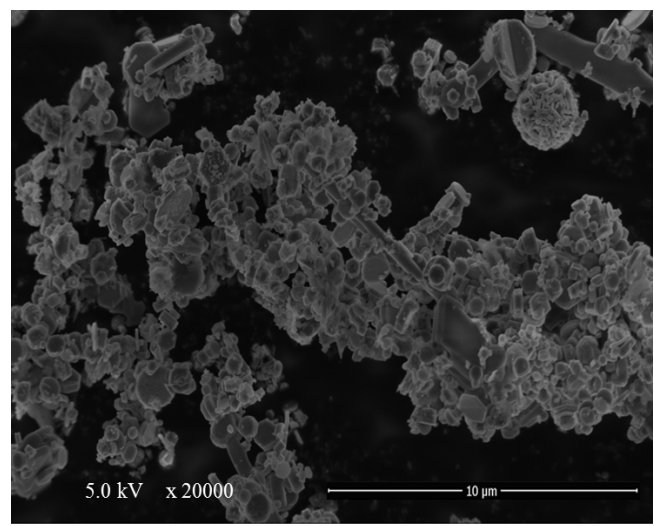

Figure 1: SEM image of the zinc oxide dust sample.
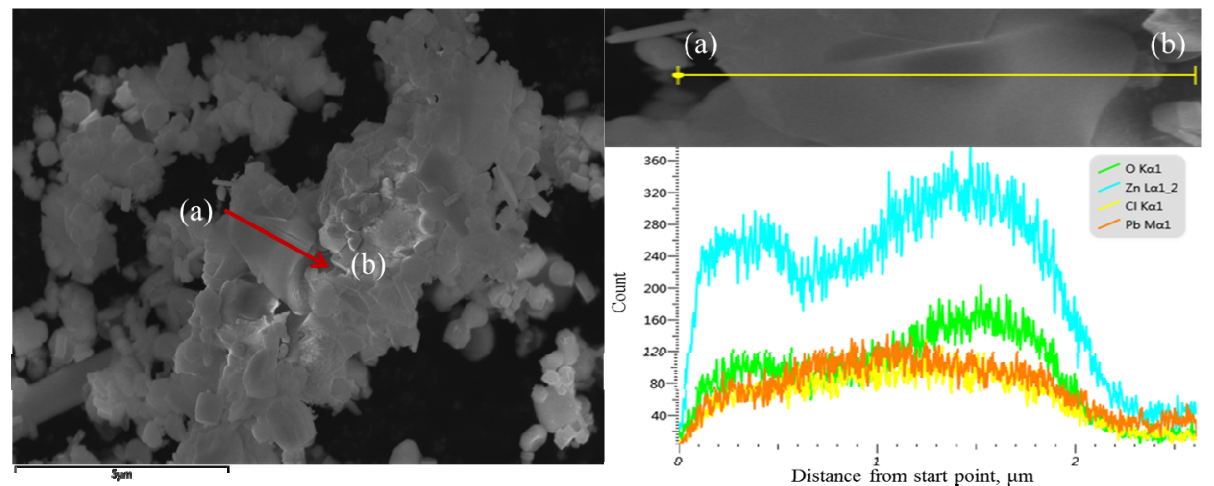

Figure 2: EDS line scanning results for the zinc oxide dust sample (red line).
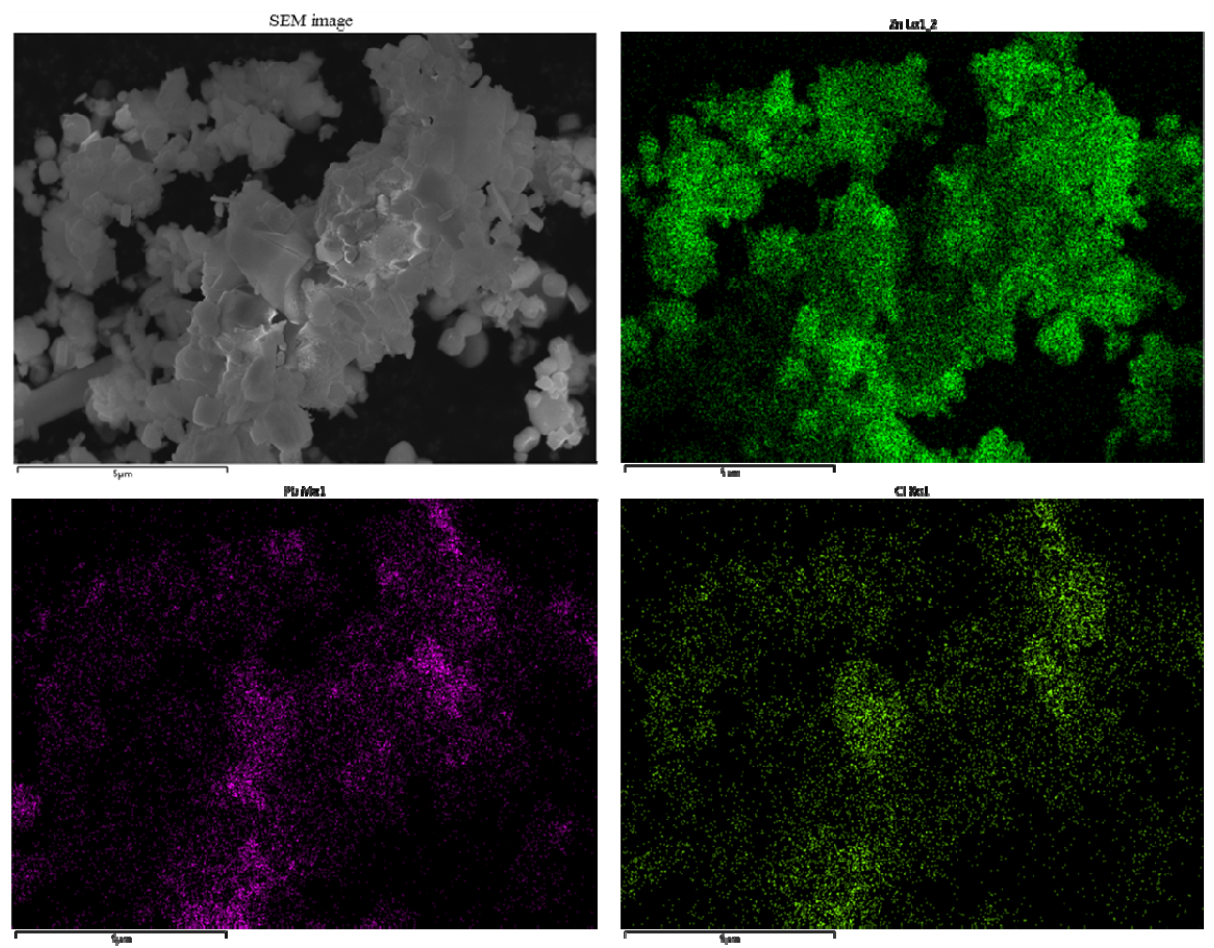

Figure 3: SEM image (Backscattered Electron Image) of zinc oxide dust and the zinc, lead and chlorine X-ray EDS mapping. 


\section{Experimental Set-up}

A 3-kW box-type microwave reactor developed by the Key Laboratory of Unconventional Metallurgy in the Ministry of Education of Kunming University of Science and Technology was utilized for the experiments. The schematic of the experimental set up is shown in Figure 4.

The microwave heating frequency was 2450 $\mathrm{MHz}$, while the power could be varied from $0 \mathrm{~kW}$ to $3 \mathrm{~kW}$. A thermocouple with shielded sleeves was used to measure the temperature, in the range of $0{ }^{\circ} \mathrm{C}$ to $1300{ }^{\circ} \mathrm{C}$. A mullite crucible with an inner diameter of $90 \mathrm{~mm}$, height of $120 \mathrm{~mm}$, having good wavetransparency and heat shock properties was used as the material support. The device was equipped with a mixing system, of 0 to $120 \mathrm{rpm}$, to facilitate intense mixing of the zinc oxide dust. A dust absorption system was developed to collect the flue dust generated in the experimental process. This system was comprised of a dust collection bottle, a water bottle, an alkali-absorption bottle, a buffer bottle, and a miniature pump.

\section{Experimental Method}

$300 \mathrm{~g}$ of sample was dried, ground and placed into the mullite crucible, which was surrounded with heat preservation material. All of these materials were then transferred to a microwave reactor, and the start of the experiment was marked by activating the microwave, stirring, and out-gas absorption systems. The microwave output power was $900 \mathrm{~W}$, and the zinc oxide dust average heating rate were $90^{\circ} \mathrm{C} / \mathrm{min}$. Water vapor along with air was passed into the reactor after the material was heated to the set roasting temperature. The flow rate of steam and air into the reactor was controlled by adjusting the power to the electrical heating jacket. The mixing system facilitates the reaction, enabling release of chloride components. The tail gas absorption system promptly discharged volatile gas from the microwave cavity. The effect of different roasting temperatures, holding times, and stirring speeds on $\%$ chlorine removal was investigated under different air and steam flow rates.

\section{Calculation of the Cl Removal Rate from Zinc Oxide Dust}

After the microwave roasting, the zinc oxide dust samples were cooled to room temperature and the silver chloride turbidimetric method (Zenki and Iwadou 2002) was used for determination of the chlorine content. The $\%$ chlorine removal was expressed as:

$\eta_{(C l)}=\frac{C_{(C l)}-C^{\prime}(C l)}{C_{(C l)}} \times 100 \%$

where $C_{(C l)}$ represents the initial chloride content in the zinc oxide dust; $C^{\prime}{ }_{(C l)}$ denotes the $\mathrm{Cl}$ content in the zinc oxide dust after roasting; and $\eta_{(C l)}$ represents $\% \mathrm{Cl}$ removal.

\section{RESULTS AND DISCUSSION}

\section{Thermomechanical Analysis}

The determination of fluoride in the dust samples was performed using a fluoride ion-selective electrode (Tokalioglu, 2004). Because the F content was less than $0.01 \%$ based in the analysis of the zinc oxide dust composition, which meets the electrolysis requirements, the following experiments involved only dechlorination via microwave roasting.

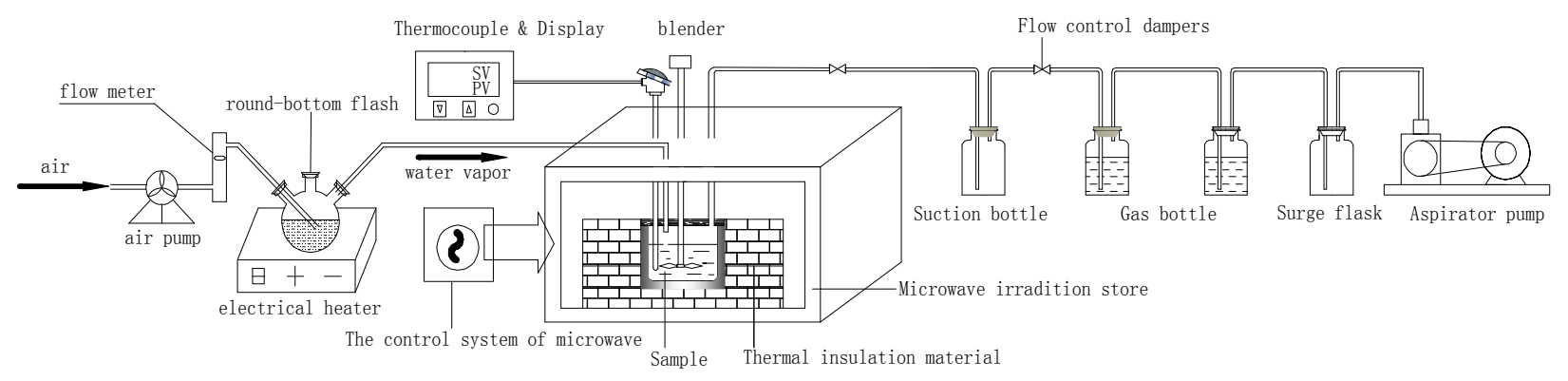

Figure 4: Connection diagram of the microwave-roasting equipment. 
The composition of dust is complex, as evidenced from the contents reported in Table $1 . \mathrm{Pb}$ and $\mathrm{Zn}$ halides are volatile and have good microwave absorbing properties. The increase in temperature through microwave roasting converts the solid metal chloride into the gas phase, enabling its removal from the solid matrix. The formation of halides $\left(\mathrm{ZnCl}_{2}\right.$, $\mathrm{PbCl}_{2}$ ) from zinc oxide dust under high-temperature volatilization can be expressed as shown in Eq. (2):

$$
\mathrm{MeX}_{2}(s)=\mathrm{MeX}_{2}(\mathrm{~g})
$$

where $\mathrm{Me}$ represents $\mathrm{Pb}^{2+}$ and $\mathrm{Zn}^{2+}$ and $X$ denotes $\mathrm{Cl}^{-}$. The melting point, boiling point, and vapor pressure of main-group halides in zinc oxide dust are listed in Table 2 (Fu, 1997). $\mathrm{ZnCl}_{2}$ and $\mathrm{PbCl}_{2}$ have relatively low boiling and melting points, and hence these elements are relatively easy to volatilize. Therefore, the $\mathrm{Pb}$ and $\mathrm{Zn}$ chloride vapor pressure is expected to increase rapidly at temperatures exceeding $650{ }^{\circ} \mathrm{C}$.

Zinc oxide dust also contains a small amount of sulfur, and the theoretical aspects of halide thermal hydrolysis and sulfate reaction are examined in this study (Zeng et al., 2007; Li et al., 2010; Li et al., 2009):

$$
\begin{aligned}
& M e X_{2}+\mathrm{H}_{2} \mathrm{O}=M e \mathrm{O}+2 \mathrm{HX}(\mathrm{g}) \\
& M e X_{2}+\mathrm{H}_{2} \mathrm{O}+1 / 2 \mathrm{O}_{2}+\mathrm{SO}_{2}= \\
& \mathrm{MeSO}_{4}+2 \mathrm{HX}(\mathrm{g})
\end{aligned}
$$

where $\mathrm{Me}$ represents $\mathrm{Pb}^{2+}$ and $\mathrm{Zn}^{2+}$ and $\mathrm{X}$ denotes $\mathrm{Cl}^{-}$.

Table 3 shows the Gibbs free energies $\left(\mathrm{kJ} \cdot \mathrm{mol}^{-1}\right)$ for $\mathrm{Pb}$ and $\mathrm{Zn}$ chloride thermal hydrolysis and the sulfate reaction in the temperature range of $600{ }^{\circ} \mathrm{C}$ to $900{ }^{\circ} \mathrm{C}$. Table 4 shows the equilibrium constants for $\mathrm{Pb}$ and $\mathrm{Zn}$ chloride chemical reaction in the range of $600{ }^{\circ} \mathrm{C}$ to $800^{\circ} \mathrm{C}$.

Tables 3 and 4 (Zeng et al., 2007) show that the Gibbs free energy of the sulfate reaction is at its minimum and equilibrium constant is at its maximum, indicating the ease of conducting the sulfate reaction as compared with thermal hydrolysis. The Gibbs free energy increases significantly with an increase in temperature, and hence it is favorable to conduct the dechlorination reactions at low roasting temperature. The effect of roasting temperature control and the recycling of valuable metals were also additionally reported in the present work (Zhang et al., 2011; Wang et al., 2007).

The following reaction occurs in the presence of air at high temperatures:

$$
\mathrm{MeX}_{2}(\mathrm{~g})+1 / 2 \mathrm{O}_{2}(\mathrm{~g})=\mathrm{MeOX}(\mathrm{g})+1 / 2 X_{2}(\mathrm{~g})
$$

where $M e$ represents $\mathrm{Pb}^{2+}$ and $\mathrm{Zn}^{2+}$ and $\mathrm{X}$ denotes $\mathrm{Cl}^{-}$.

One possible reason is that oxygen gas affects the elementary evaporation reaction directly, like a catalytic effect. There are many types of ionic species containing zinc in the melt and some of them might have a strong affinity with the oxide ion.

Table 2: Melting point, boiling point, and vapor pressure of main-group halides in zinc oxide dust.

\begin{tabular}{|c|c|c|c|c|c|c|c|}
\hline Compound & Melting Point & Boiling Point & \multicolumn{5}{|c|}{ Vapor Pressure (Pa) } \\
\cline { 4 - 8 } & $\left({ }^{\circ} \mathbf{C}\right)$ & $\left({ }^{\circ} \mathbf{C}\right)$ & $\mathbf{5 5 0}^{\circ} \mathbf{C}$ & $\mathbf{6 5 0}^{\circ} \mathbf{C}$ & $\mathbf{7 5 0}^{\circ} \mathbf{C}$ & $\mathbf{8 5 0}^{\circ} \mathbf{C}$ & $\mathbf{9 5 0}^{\circ} \mathbf{C}$ \\
\hline $\mathrm{ZnCl}_{2}$ & 365 & 732 & $4.38 \times 10^{3}$ & $3.15 \times 10^{4}$ & $1.46 \times 10^{5}$ & $4.93 \times 10^{5}$ & $1.32 \times 10^{6}$ \\
$\mathrm{PbCl}_{2}$ & 501 & 952 & $1.54 \times 10^{2}$ & $1.49 \times 10^{3}$ & $8.59 \times 10^{3}$ & $3.43 \times 10^{4}$ & $1.01 \times 10^{5}$ \\
\hline
\end{tabular}

Table 3: Gibbs free energies $\left(\mathrm{kJ} \cdot \mathrm{mol}^{-1}\right)$ for $\mathrm{Pb}$ and $\mathrm{Zn}$ chloride thermal hydrolysis and sulfate reactions.

\begin{tabular}{|c|c|c|c|c|c|c|c|c|}
\hline \multirow{3}{*}{ Matter } & \multicolumn{4}{|c|}{ Thermal hydrolysis reaction } & \multicolumn{4}{c|}{ Sulfate reaction } \\
\cline { 2 - 9 } & $\mathbf{6 0 0}^{\circ} \mathbf{C}$ & $\mathbf{7 0 0}^{\circ} \mathbf{C}$ & $\mathbf{8 0 0}^{\circ} \mathbf{C}$ & $\mathbf{9 0 0}^{\circ} \mathbf{C}$ & $\mathbf{6 0 0}^{\circ} \mathbf{C}$ & $\mathbf{7 0 0}^{\circ} \mathbf{C}$ & $\mathbf{8 0 0}^{\circ} \mathbf{C}$ & $\mathbf{9 0 0}^{\circ} \mathbf{C}$ \\
\hline $\mathrm{ZnCl}_{2}$ & 27.44 & 18.65 & 18.27 & 21.38 & -62.71 & -43.79 & -19.23 & -9.31 \\
$\mathrm{PbCl}_{2}$ & 104.66 & 97.69 & 90.95 & 83.16 & -67.90 & -48.22 & -27.36 & -14.72 \\
\hline
\end{tabular}

Table 4: Equilibrium constants for $\mathrm{Pb}$ and $\mathrm{Zn}$ chloride chemical reactions.

\begin{tabular}{|c|c|c|c|c|c|c|c|c|c|}
\hline \multirow{2}{*}{ Matter } & \multicolumn{3}{|c|}{ Volatile reaction } & \multicolumn{3}{c|}{ Thermal hydrolysis reaction } & \multicolumn{3}{c|}{ Sulfate reaction } \\
\cline { 2 - 10 } & $\mathbf{6 0 0}^{\circ} \mathbf{C}$ & $\mathbf{7 0 0}^{\circ} \mathbf{C}$ & $\mathbf{8 0 0}^{\circ} \mathbf{C}$ & $\mathbf{6 0 0}^{\circ} \mathbf{C}$ & $\mathbf{7 0 0}^{\circ} \mathbf{C}$ & $\mathbf{8 0 0}^{\circ} \mathbf{C}$ & $\mathbf{6 0 0}^{\circ} \mathbf{C}$ & $\mathbf{7 0 0}^{\circ} \mathbf{C}$ & $\mathbf{8 0 0}^{\circ} \mathbf{C}$ \\
\hline $\mathrm{ZnCl}_{2}$ & 0.121 & 0.699 & 2.719 & 0.023 & 0.10 & 0.13 & 5651.63 & 224.45 & 8.63 \\
$\mathrm{PbCl}_{2}$ & $5.06 \times 10^{-3}$ & $3.67 \times 10^{-2}$ & 0.172 & $5.46 \times 10^{-7}$ & $5.52 \times 10^{-6}$ & $3.74 \times 10^{-5}$ & $1.16 \times 10^{4}$ & 387.78 & 21.46 \\
\hline
\end{tabular}


The lead and zinc halide volatilization rate initially increases with the increase in temperature, with the maximum around approximately $727^{\circ} \mathrm{C}$. Therefore, an exorbitantly high roasting temperature is unfavorable in the roasting process. Additionally, high temperature results in a loss of valuable metals such as $\mathrm{Zn}$ and $\mathrm{Pb}$ due to volatilization.

Hydrolysis and microwave roasting reactions were conducted to identify the optimal dechlorination process conditions through microwave roasting. These optimal process conditions were targeted to reduce the energy consumption and reaction duration and to increase the $\%$ dechlorination.

\section{Effect of Air Flow Rate}

The roasting temperature and duration were held constant at $650{ }^{\circ} \mathrm{C}$ and $60 \mathrm{~min}$, respectively. The samples were stirred at a speed of $60 \mathrm{rpm}$. The reduction in actual chlorine content along with \% reduction at different air flow rates are shown in Figure 5 . The $\%$ chlorine removal was found to be around $50 \%$ for the flow rate of $200 \mathrm{~L} / \mathrm{h}$, which was observed to marginally increase to $55 \%$ at $300 \mathrm{l} / \mathrm{h}$. However at flow rates higher than $300 \mathrm{~L} / \mathrm{h}$ an exponential increase was observed. An increase in the air flow rate contributes to stronger energy dissipation from the system, demanding higher energy inputs to maintain the reaction temperature. Hence, in order to reduce the energy consumption, it is desirable to operate at a moderate airflow. Additionally, at high airflow rates, physical carryover of the samples was observed.

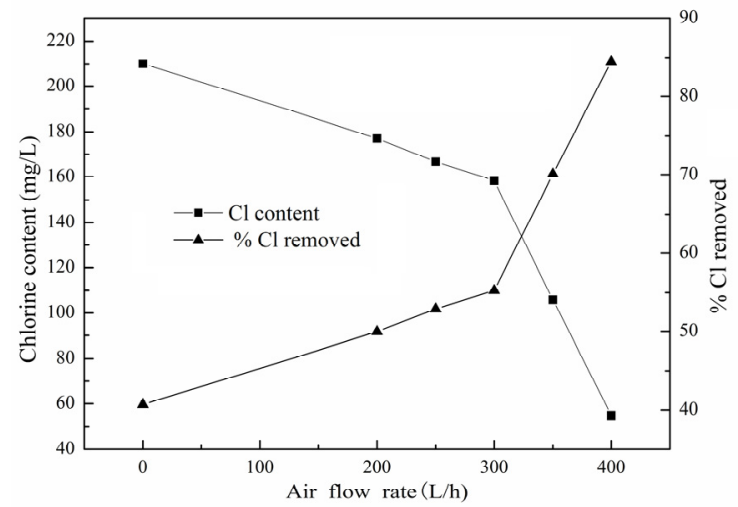

Figure 5: Effect of air flow rate on $\mathrm{Cl}$ content and removal rate.

\section{Effect of Steam Flow Rate}

Figure 6 shows the actual dechlorination along with the $\%$ dechlorination of zinc oxide dust with the increase in the steam flow rate at a roasting temperature of $600{ }^{\circ} \mathrm{C}$, duration of $60 \mathrm{~min}$, air flow rate of $300 \mathrm{l} / \mathrm{h}$ and a stirring rpm of 60 .

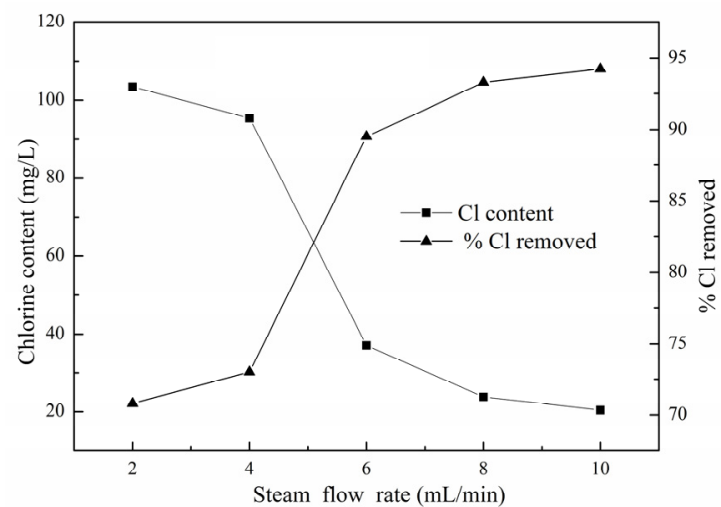

Figure 6: Effect of steam flow rate on $\mathrm{Cl}$ content and removal rate.

An increase in the steam flow rate was found to increase the $\%$ dechlorination significantly, with the maximum \% removal of near $95 \%$ at a flow rate of $10 \mathrm{~mL} / \mathrm{min}$. However, the rate of removal was observed to be very high up to a steam flow rate of $8 \mathrm{ml} / \mathrm{min}$, while it reduced significantly beyond this value. The high $\%$ dechlorination could be attributed to the increased rate of thermal hydrolysis and to sulfate reactions with formation of hydrogen halide gas. Hence, an optimal steam flow rate of $8 \mathrm{ml} / \mathrm{min}$ was utilized to assess the effect of other parameters.

\section{Effect of Stirring Speed}

$300 \mathrm{~g}$ of zinc oxide dust was dechlorinated for $1 \mathrm{~h}$ at $650{ }^{\circ} \mathrm{C}$ under a steam flow rate of $8 \mathrm{~mL} / \mathrm{min}$ and at an air flow rate of $300 \mathrm{~L} / \mathrm{h}$. Figure 7 presents the actual chlorine removal as well as the $\%$ dechlorination for stirrer speeds of 20 to $100 \mathrm{rpm}$.

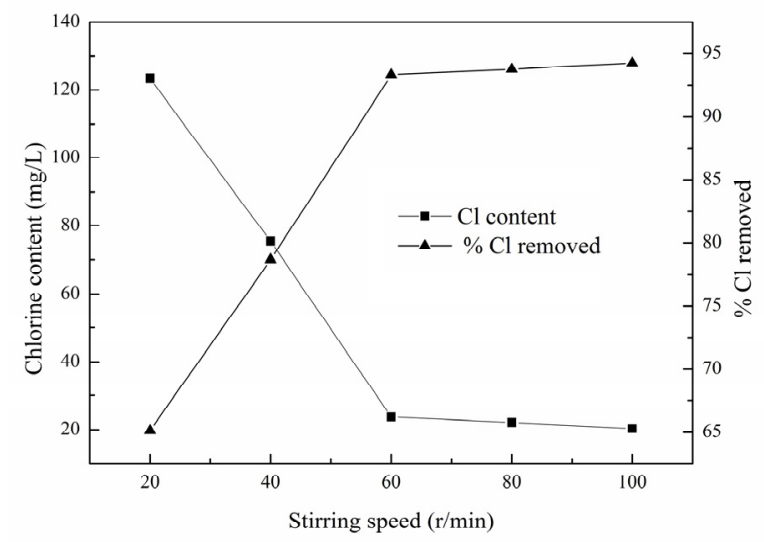

Figure 7: Effect of stirring speed on $\mathrm{Cl}$ content and removal rate.

The dechlorination was found to increase signifi- 
cantly up to $60 \mathrm{rpm}$, while no significant improvement was observed at rpms in excess of 60. At low rpm, the mixing is not sufficient to generate sufficient interphase area, hence limiting the extent of conversion. The reduction in mass transfer resistance due to the increase in surface renewal rate up to $60 \mathrm{rpm}$ contributes to the increase in \% dechlorination. At rpms in excess of 60 , no significant increase in \% dechlorination was observed, possibly due to complete mixing and elimination of mass transfer resistance.

Therefore, the appropriate mixing speed facilitates more even the microwave irradiation on the surface of zinc oxide dust, increasing the contact area between microwaves and zinc oxide dust and enhancing heat transfer.

\section{Effect of Roasting Temperature}

Figure 8 presents the effect of roasting temperature with the other operating parameters held at a roasting duration of $1 \mathrm{~h}, 60 \mathrm{rpm}$, air flow rate of $300 \mathrm{~L} / \mathrm{h}$ and steam flow rate of $8 \mathrm{ml} / \mathrm{min}$. The chlorine removal rate was observed to increase exponentially at temperatures higher than $550{ }^{\circ} \mathrm{C}$, with a total removal of near $95 \%$ at $650{ }^{\circ} \mathrm{C}$. Further increase in the temperature beyond $650{ }^{\circ} \mathrm{C}$ was not found to have any effect on the $\%$ dechlorination. An increase in the rate of reaction and eventually a shift in the reaction equilibrium could have contributed to the increase in the conversion. At temperatures in excess of $650{ }^{\circ} \mathrm{C}$ a physical loss of $\mathrm{Pb}$ and $\mathrm{Zn}$ could be observed. Hence an optimal roasting temperature of $650{ }^{\circ} \mathrm{C}$ was utilized for assessing the effect of the other parameters.

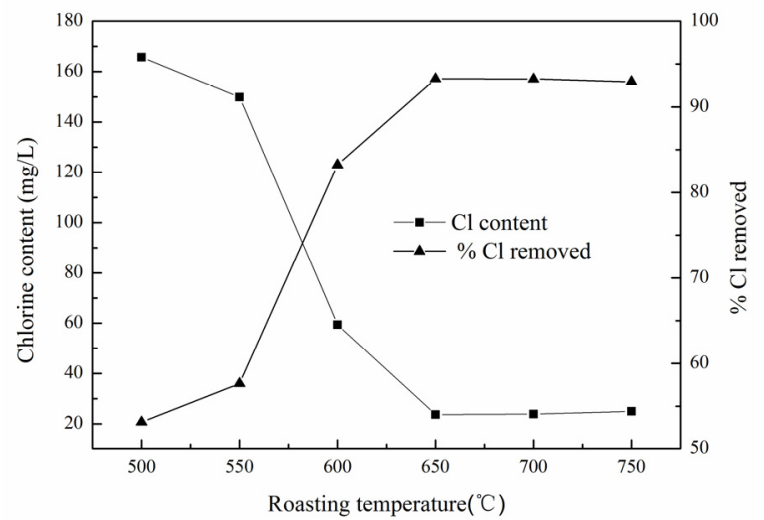

Figure 8: Effect of roasting temperature on $\mathrm{Cl}$ content and removal rate

\section{Effect of Holding Time}

Figure 9 shows the effect of roasting duration, with the other parameters held constant at a steam flow rate of $8 \mathrm{~mL} / \mathrm{min}$, air flow rate of $300 \mathrm{~L} / \mathrm{h}$, tempera- ture of $650{ }^{\circ} \mathrm{C}$, and at stirring speed of $60 \mathrm{rpm}$.

The dechlorination was observed to increase at a high rate until 60 minutes, while it increased only marginally beyond. A total $\%$ dechlorination of near $95 \%$ could be attained at a roasting duration of 100 min. An increase in the duration of roasting contributes to the increase in the $\%$ dechorination due to the increase in the extent of the thermal hydrolysis, as well as the sulfate reactions. Since the rate of removal was much slower at times longer than $60 \mathrm{~min}$, an optimal duration of $60 \mathrm{~min}$ was utilized for all other experiments.

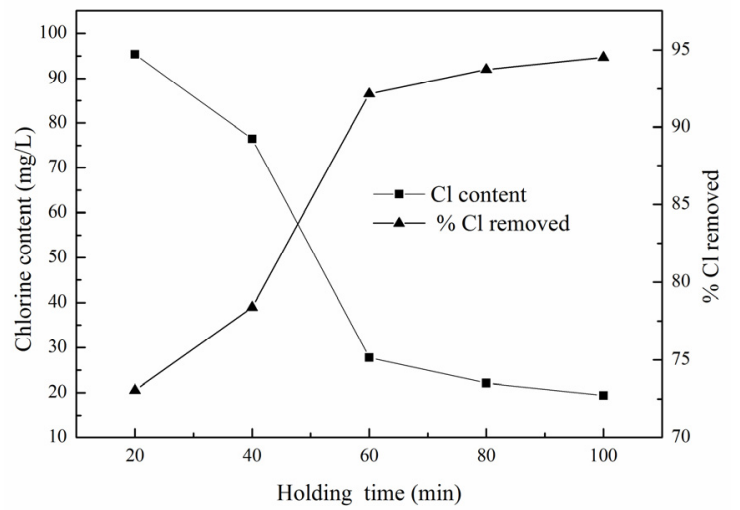

Figure 9: Effect of holding time on chlorine content and removal rate.

\section{Optimal Experiment}

The aim of this study was to investigate the values of the five operational parameters (air flow rate, steam flow rate, stirring speed, roasting temperature, and holding time) that maximize the dechlorination efficiency. Through this study, the optimal parameters and experimental result were obtained and are given in Table 5.

The results show that zinc oxide dust treated by microwave roasting could definitely satisfy the demands of chlorine content in the electrode processing of zinc; the chlorine concentration is $23 \mathrm{mg} / \mathrm{L}$ in the leaching liquid. Compared with roasting in multiple hearth furnaces and in a rotary kiln, as well as the method of alkali cleaning, the microwave roasting treatment shows more advantages.

Compared with the traditional dechlorination process, the non-conventional process of microwave roasting for dechlorination of zinc oxide dust is simpler, cleaner and more pollution-free. In addition, the chlorine content in the leaching solution met the zinc electro-winning requirements in the subsequent leaching process. Table 6 shows the control conditions and comparisons of several dechlorination processes (Güresin and Topkaya, 1998; Cinar Sahin et al., 2000; Wei et al., 2014). 
Table 5: Optimization parameters from the experimental results.

\begin{tabular}{|c|c|c|c|c|c|}
\hline $\begin{array}{c}\text { Air Flow Rate } \\
(\mathbf{L} / \mathbf{h})\end{array}$ & $\begin{array}{c}\text { Steam Flow Rate } \\
(\mathbf{m L} / \mathbf{m i n})\end{array}$ & $\begin{array}{c}\text { Stirring Speed } \\
(\mathbf{r p m})\end{array}$ & $\begin{array}{c}\text { Roasting } \\
\text { Temperature } \\
\left({ }^{\circ} \mathbf{C}\right)\end{array}$ & $\begin{array}{c}\text { Holding Time } \\
(\mathbf{m i n})\end{array}$ & $\begin{array}{c}\text { Dechlorination Rate } \\
(\%)\end{array}$ \\
\hline 300 & 8 & 60 & 650 & 60 & 93.5 \\
\hline
\end{tabular}

Table 6: The comparison of different methods for dechlorination.

\begin{tabular}{|l|c|c|l|}
\hline \multicolumn{1}{|c|}{ Process } & $\begin{array}{c}\text { Temperature } \\
{ }^{\circ} \mathbf{C}\end{array}$ & $\begin{array}{c}\text { Time } \\
\text { h }\end{array}$ & \multicolumn{1}{c|}{ Advantages and disadvantages } \\
\hline $\begin{array}{l}\text { Rosting in multiple } \\
\text { hearth furnaces }\end{array}$ & $600-1000$ & $0.5-4$ & $\begin{array}{l}\text { (1) the most mature method } \\
\text { (2) huge equipment; high investment; high energy consumption; } \\
\text { high cost of center shaft damage repair }\end{array}$ \\
\hline $\begin{array}{l}\text { Water washing, } \\
\text { Caustic washing }\end{array}$ & $80-95$ & $2-4$ & $\begin{array}{l}\text { (1) Easy manipulation; low cost } \\
\text { (2) large consumption of NaCO }{ }_{3} \text { caustic soda and vapor } \\
\text { (3) Produces large amounts of waste water, the liquid after water } \\
\text { washing or caustic washing must be processed appropriately to } \\
\text { achieve the plant emission requirements, the need for a large } \\
\text { amount of water and sulfuric acid. }\end{array}$ \\
\hline Microwave Roasting & $550-750$ & $0.5-1.0$ & $\begin{array}{l}\text { Clean and non-polluting, low energy consumption, heating } \\
\text { selectivity, short reaction time and easy operation. }\end{array}$ \\
\hline
\end{tabular}

Thus, studying a new method of removing chlorine by microwave roasting is of great significance for the development and utilization of zinc dust resources, as well as its reuse and comprehensive recovery. Moreover, it also has the potential advantage of energy conservation and reduction in consumption in the zinc hydrometallurgy process.

The results show that zinc oxide dust treated by microwave roasting could definitely satisfy the demands of chlorine content in the electrode processing of zinc; the chlorine concentration is $23 \mathrm{mg} / \mathrm{L}$ in the leaching liquid. Compared with roasting in multiple hearth furnaces and in a rotary kiln, as well as the method of alkali cleaning, the microwave roasting treatment shows more advantages.

Compared with the traditional dechlorination process, the non-conventional process of microwave roasting for dechlorination of zinc oxide dust is simpler, cleaner and more pollution-free. In addition, the chlorine content in the leaching solution met the zinc electro-winning requirements in the subsequent leaching process. Table 6 shows the control conditions and comparisons of several dechlorination processes (Güresin and Topkaya, 1998; Cinar Sahin et al., 2000; Wei et al., 2014).

Thus, studying a new method of removing chlorine by microwave roasting is of great significance for the development and utilization of zinc dust resources, as well as its reuse and comprehensive recovery. Moreover, it also has the potential advantage of energy conservation and reduction in consumption in the zinc hydrometallurgy process.

\section{CONCLUSIONS}

(1) The results obtained in the present experimental study showed that high-Cl zinc oxide dust could be treated effectively by microwave roasting. A near $93 \%$ dechlorination of zinc oxide dust could be achieved, which would satisfy the requirements of the wet smelting electrolysis process. The optimal process parameters were identified to be an air flow of $300 \mathrm{~L} / \mathrm{h}$, a steam flow of $8 \mathrm{~mL} / \mathrm{min}$, a stirring speed of $60 \mathrm{rpm}$, a roasting temperature of $650{ }^{\circ} \mathrm{C}$, and a roasting duration of $60 \mathrm{~min}$.

(2) Roasting under air and water vapor contributed to $\mathrm{Cl}$ removal in high- $\mathrm{Cl}$ zinc oxide dust. The activation of water vapor in microwave roasting resulted in a residual $\mathrm{Cl}$ content of $23 \mathrm{mg} / \mathrm{L}$ in the solution. This meets the $\mathrm{Cl}$ content required for leached solutions in the production of electrolytic zinc.

(3) Based on the thermomechanical analysis and experimental results, water vapor has an enhanced effect on dechlorination by microwave roasting.

\section{ACKNOWLEDGEMENTS}

The authors are grateful for the financial support from the National Program on Key Basic Research Project of China (973 Program, 2014CB643404), the National Natural Science Foundation (No. 51104073), the Yunnan Province Young Academic Technology Leader Reserve Talents (2012HB008), the Yunnan 
Provincial Science and Technology Innovation Talents scheme Technological Leading Talent (2013HA002), and the $2014 \mathrm{PhD}$ Newcomer Award in Yunnan Province (2014).

\section{NOMENCLATURE}

$\begin{array}{ll}M_{(\mathrm{Cl})} & \begin{array}{l}\text { Raw material chloride content in zinc oxide } \\ \text { dust }(\mathrm{mg} / \mathrm{L})\end{array} \\ M^{\prime}{ }_{(\mathrm{Cl})} & \begin{array}{l}\text { chloride content in zinc oxide dust after } \\ \text { roasting }(\mathrm{mg} / \mathrm{L})\end{array} \\ \eta_{(\mathrm{Cl})} & \begin{array}{l}\% \mathrm{Cl} \text { removal } \\ \mathrm{T}\end{array} \\ \mathrm{t} & \text { Temperature }\left({ }^{\circ} \mathrm{C}\right) \\ \text { time (min) }\end{array}$

\section{REFERENCES}

Altundoğan, H. S., Erdem, M., Orhan, R., Özer, A. and Tümen, F., Heavy metal pollution potential of zinc leach residues discarded in Çinkur plant. Turkish Journal Engineering Environmental Sciences, 22, 167-177 (1998).

Bodson, F. J. J., Process for the elimination of chloride from zinc sulphate solution. US Patent, Appl. 4005174(1977).

Cinar Sahin, F., Derin, B. and Yücel, O., Chloride removal from zinc ash. Scandinavian Journal of Metallurgy, 29(5), 224-230 (2000).

Chen, J., Liu, L., Zeng, J. Q., Ren, R. G. and Liu, J. Y., Metallography of iron coal containing ore concentrates reduced by microwave heating. Journal of Chinese Electron Microscopy Society, 24(2), 114-119 (2005). (In Chinese).

Fu, Y. M., Defluorination and dechlorination of zinc oxide dust from lead fuming furnace. Northestern University, 11-14 (1997).

Güresin, N. and Topkaya, Y. A., Dechlorination of a zinc dross. Hydrometallurgy, 49(1-2), 179-187 (1998).

Harahsheh, M. A. and Kingman, S. W., Microwaveassisted leaching: A review. Hydrometallurgy, 73, (3-4), 189-203 (2004).

Jha, M. K., Kumar, V. and Singh, R. J., Review of hydrometallurgical recovery of zinc from industrial wastes. Resources, Conservation and Recycling, 33(1), 1-22 (2001).

Jiang, L., Fu, G. F. and Wang, D. Q., Removal of F and $\mathrm{Cl}$ from zinc oxide dust using selective chlorination roasting process. Nonferrous Metals, 53(3), 28-31 (2001). (In Chinese).

Jones, D. A., Kingman, S. W. and Whittles, D. N., The influence of microwave energy delivery method on strength reduction in ore samples. Chemical Engineering and Processing, 46(4), 291-299 (2007).

Li, M., Peng, B., Chai, L. Y., Peng, N., Yan, H. and Hou, D. K., Recovery of iron from zinc leaching residue by selective reduction roasting with carbon. Journal of Hazardous Materials, 237-238, 323-330 (2012).

Lan, Y. Z., Zhao, Q. R. and Smith, R. W., Recovery of zinc from high fluorine bearing zinc oxide ore. Mineral Processing and Extractive Metallurgy, 115(2), 117-119 (2006).

Liang, G. A., Peng, J. H., Bai, S., Zhang, S. M., Li, J., Guo, S. H., Li, X. P. and Liang, W., Research on control system of microwave pretreatment of selenium rich slag. Journal of Kunming University of Science and Technology (Natural Science Edition), 36(2), 16-19 (2011). (In Chinese).

Li, R. D., Li, Y. L., Wang, L., Tian, X. H., Ke, X., Wei, L. L. and Yang, T. H., Kinetic and thermodynamic study of $\mathrm{ZnCl}_{2}$ volatilizing in air atmosphere. Journal of Combustion Science and Technology, 16(1), 30-34 (2010). (In Chinese).

Li, R. D., Li, Y. L., Wang, L., Zhang, H. J., Ke, X. and Wei, L. L., Kinetic and thermodynamic study of $\mathrm{PbCl}_{2}$ volatilizing in air atmosphere. Journal of Thermal Science and Technology, 8(1), 57-63 (2009). (In Chinese).

Min, X. B., Xie, X. D., Chai, L. Y., Lang, Y. Y., Li, $\mathrm{M}$. and $\mathrm{Ke}, \mathrm{Y}$., Environmental availability and ecological risk assessment of heavy metals in zinc leaching residue. Transactions of Nonferrous Metals Society of China, 23(1), 208-218 (2013).

Martins, R. J. E., Vilar, V. J. P. and Boaventura, R. A. R., Kinetic modelling of cadmium and lead removal by aquatic mosses. Brazilian Journal of Chemical Engineering, 31(01), 229-242 (2014).

Mason, C. R. S., Harlamovs, J. R., Dreisinger, D. B. and Grinbaum, B., Solvent extraction of a halide from a aqueous sulphate solution. US Patent, Appl. 7037482B2 (2006).

Onol, K. and Saridede, M. N., Investigation on microwave heating for direct leaching of chalcopyrite ores and concentrates. International Journal of Minerals, Metallurgy and Materials, 20(3), 228233 (2013).

Peng, J. H. and Yang, X. W., The new applications of microwave power. Kun Ming: Yunnan Science and Technology Press (1997). (In Chinese).

Qiu, Y. Y., Zhao, Y. C., Zhang, C. L. and Yi, T. S., Chlorine removal from zinc bearing wastes in alkaline leaching electrowinning process. Journal of Safety and Environment, 8(1), 62-64 (2008). (In Chinese). 
Souza, A. D., Pina, P. S. and Leao, V. A., Bioleaching and chemical leaching as an integrated process in the zinc industry. Minerals Engineering, 20(6), 591-599 (2007).

Salsman, J. B., Williamson, R. L., Tolley, W. K. and Rice, D. A., Short-pulse microwave treatment of disseminated sulfide ores. Minerals Engineering, 9(1), 43-54 (1996).

Tokalioglu, S., Kartal, S., Sahin, U., The determination of fluoride in the dust samples was performed using a fluoride ion-selective electrode. Turkish Journal of Chemistry, 28(2), 203-211 (2004).

Vahidi, E., Rashchi, F. and Moradkhani, D., Recovery of zinc from an industrial zinc leach residue by solvent extraction using D2EHPA. Minerals Engineering, 22(2), 204-206 (2009).

Wang, C. G., Hu, X. J., Matsuura, H. and Tsukihashi, F., Evaporation kinetics of the molten $\mathrm{PbCl}_{2}-$ $\mathrm{ZnCl}_{2}$ system from 973 to $1073 \mathrm{~K}$. ISIJ International, 47(3), 370-376 (2007).

Wei, Y. Q., Peng, J. H., Zhang, L. B., Ju, S. H., Xia, Y., Zheng, Q., Wang, Y. J., Dechlorination of zinc dross by microwave roasting. Journal of Central
South University, 21(7), 2627-2632 (2014).

Xie, M. Q., Study on technique for extracting zinc and indium from reduction and volatilization zinc oxide dust. Mining and Metallurgical Engineering, 28(2), 63-65(2008). (In Chinese).

Zhao, Y. C., Li. Q., Zhang. C. L. and J. J. C., Production of ultrafine zinc powder from wastes containing zinc by electrowinning in alkaline solution. Brazilian Journal of Chemical Engineering, 30(4), 857-864 (2013).

Zenki, M. and Iwadou, Y., Repetitive determination of chloride using the circulation of the reagent solution in closed flow-through system. Talanta, 58(6), 1055-1061 (2002).

Zeng, Z. G., Dou, C. L., Liu, W. P., Xi, X. M. and Xiao, S. W., Measures to reinforce the de-halogen roasting of zinc oxide dust in multi-hearth furnace. Mining and Metallurgical Engineering, 27(1), 5456 (2007). (In Chinese).

Zhang, Y. L., Fu, Z. H., Li, S. Q., Wang, Y. G. and Fu, $\mathrm{X}$. B., Vapor pressure measurements of zinc and lead chlorides in complex system. The Chinese Journal of Nonferrous Metals, 21(2), 450-458 (2011). (In Chinese). 